Journal of Food Protection, Vol. 00, No. 00, 2009, Pages 000-000

Copyright $\odot$, International Association for Food Protection

\title{
Interaction of Escherichia coli 0157:H7 with Leafy Green Produce
}

\author{
JUAN XICOHTENCATL-CORTES, ${ }^{1}$ ETHEL SÁNCHEZ CHACÓN, ${ }^{2}$ ZEUS SALDAÑA, ${ }^{1}$ ENRIQUE FREER, ${ }^{2}$ AND \\ JORGE A. GIRÓN ${ }^{1 *}$
}

\author{
${ }^{1}$ Department of Immunobiology, University of Arizona, 1501 North Campbell Avenue, Tucson, Arizona 85724, USA; and \\ ${ }^{2}$ Centro de Investigación en Estructuras Microscópicas, Universidad de Costa Rica, San José, Costa Rica
}

MS 09-014: Received 14 January 2009/Accepted 19 March 2009

\begin{abstract}
Enterohemorrhagic Escherichia coli (EHEC) is a foodborne pathogen responsible for human diarrheal disease. EHEC lives in the intestinal tract of cattle and other farm and wild animals, which may be the source of environmental contamination particularly of agricultural fields. Human infections are associated with consumption of tainted animal products and fresh produce. How the bacteria interact with the plant phyllosphere and withstand industrial decontamination remain to be elucidated. The goals of the present study were to investigate the environmental conditions and surface structures that influence the interaction of EHEC O157:H7 with baby spinach and lettuce leaves in vitro. Independently of the production of Shiga toxin, EHEC O157:H7 colonizes the leaf surface via flagella and the type 3 secretion system (T3SS). Ultrastructural analysis of EHEC-infected leafy greens revealed the presence of flagellated bacteria, and mutation of the $f i C$ flagellin gene in EHEC EDL933 rendered the bacteria significantly less adherent, suggesting the involvement of flagella in the bacteria-leaf interaction. EDL933 mutated in the escN (ATPase) gene associated with the function of the T3SS but not in the eae (intimin adhesin) gene required for adherence to host intestinal cells had significantly reduced adherence compared with that of the parental strain. The data suggest a compelling role of flagella and the T3SS in colonization of leafy green produce. Colonization of salad leaves by EHEC strains may be a strategy that ensures survival of these bacteria in the environment and allows transmission to the human host.
\end{abstract}

Enterohemorrhagic Escherichia coli (EHEC) is a major cause of enteric disease, ranging from mild or bloody diarrhea (hemorrhagic colitis) to the deadly hemolytic uremic syndrome. Although the O157:H7 serotype of E. coli is most common in Northern America, other serotypes are a health burden in Europe, Australia, and Japan. The emerging and deadly infectious disease caused by this organism affects humans of all ages, but the young and old are the most susceptible to hemolytic uremic syndrome. E. coli O157:H7 was first recognized as a foodborne pathogen during an outbreak of severe bloody diarrhea associated with consumption of uncooked ground beef in hamburgers (21, $35,37)$. Other sources of human infection are contaminated fresh leafy greens (e.g., lettuce, alfalfa, spinach, and sprouts), fruit juices, unpasteurized milk, and drinking contaminated water (1). Cattle are natural hosts of E. coli O157:H7 and thus may contaminate agricultural grounds, including salad greens produced for human consumption (8). Free-roaming livestock and associated water runoff, in which EHEC can remain infectious for 6 months or longer, can be a major source of agricultural contamination, especially of leafy greens (40). Therefore, the likelihood of contamination of meat and agricultural foods for human consumption is significant. In 2006, two major outbreaks of foodborne illness associated with the consumption of spinach tainted with EHEC occurred in the United States. These

\footnotetext{
* Author for correspondence. Tel: 352-392-3136; Fax: 520-846-2042;
} E-mail: jagiron@ufl.edu. episodes were linked to contamination of a spinach field by EHEC-infected wild pigs roaming in the Salinas Valley in California (www.cdc.gov/ecoli/21006/september/updates/ 100606.htm). EHEC infections are of great concern to the public, health authorities, and industry because of the severe health risk and the added burden of the approximately \$405 million annual loss associated with industrial productivity and related healthcare costs (15). Further research is needed into the mechanisms by which EHEC is able to cause disease through contamination of our food supply, even after decontamination in the industrial setting.

Central to the ability of this organism to cause intestinal and kidney disease is the production of one or two Shiga toxins. These cytotoxins are produced by bacteria in the intestine, translocated to the bloodstream, and carried (presumably on white cells) to the kidney, where their cytotoxicity affects renal function $(21,35)$. EHEC colonizes and damages the gut mucosa via the development of histological attaching and effacing lesions (20). EHEC uses a specialized needlelike structure called the type 3 secretion system (T3SS) to translocate into intestinal cells the many effector proteins that act on cytoskeletal components, leading to the remodeling of the cytoskeleton and formation of attaching and effacing lesions (7). E. coli $\mathrm{O} 157: \mathrm{H} 7$ strains bind in vitro to several cultured cell types $(28,32,44)$ and in vivo to the gastrointestinal tracts of chickens, gnotobiotic piglets, newborn rabbits, and neonatal calves $(2,9,28,43)$. In adult cattle, the bacteria colonize primarily the terminal 
TABLE 1. E. coli strains employed in this study

\begin{tabular}{|c|c|c|}
\hline Strain & Notes & $\begin{array}{l}\text { Reference or } \\
\text { source }\end{array}$ \\
\hline EDL933 & Wild type O157:H7 & 37 \\
\hline EDL933seae & Intimin mutant & 11 \\
\hline EDL933 $\operatorname{escN}$ & T3SS-ATPase & 19 \\
\hline$\Delta \operatorname{esc} N(\mathrm{pEscN})$ & Complemented mutant & This study \\
\hline EDL933 $\mathrm{fliC}$ & Flagella mutant & 13 \\
\hline $86-24$ & Wild type O157:H7 & 45 \\
\hline $86-24 \Delta f l i C$ & Flagella mutant & This study \\
\hline $85-170$ & Wild type O157:H7 & 47 \\
\hline DH5 $\alpha$ & $\mathrm{K}-12$ & Our collection \\
\hline
\end{tabular}

rectoanal junction of the gastrointestinal tract (31). Several EHEC adherence factors have been proposed, among which an outer membrane protein (intimin) plays an important role in in vivo colonization $(11,14,23,28,38)$. Several fimbriae also have been identified in EHEC strains; however, the role of most of these pili in bovine or human host colonization is unknown $(5,24,25,36,41,46,48)$. It also is not clear which of these factors is required for attachment of the bacteria to plant cells. Shaw et al. (39) reported that the T3SS, in particular the EspA filament associated with it, was required for colonization of Eruca vesicaria (arugula) leaves by EHEC O157:H7 strains. In addition to the EspA filament, several other fibrillar structures such as flagella were involved in adhesion of EHEC O26 strains to these leaves. The flagella of Salmonella enterica serovar Senftenberg, but not serovars Arizona or Agona, also promote leaf colonization (4).

The occurrence of several episodes of human EHEC infections associated with spinach and leafy green vegetables indicates that the bacteria present on these products withstand natural environmental conditions intrinsic to agricultural fields and industrial interventions designed to decontaminate the produce before it is packaged for human consumption. The goal of the present study was to investigate the environmental conditions and the mechanisms involved in the interaction of EHEC O157:H7 with baby spinach and lettuce leaves in vitro.

\section{MATERIALS AND METHODS}

Bacterial strains and culture conditions. Wild type EHEC O157:H7 strains EDL933, 86-24, and 85-170 (Shiga toxin negative) were utilized in spinach and lettuce colonization studies (Table 1). These clinical strains were isolated from hemorrhagic colitis cases in the United States and are used as prototypic strains by many researchers (21). The laboratory nonpathogenic E coli K-12 strain DH5 $\alpha$ was used as a negative control. Bacteria were routinely grown overnight at $37^{\circ} \mathrm{C}$ with aeration in Luria-Bertani (LB) broth or Dulbecco's minimal Eagle medium (DMEM) (Invitrogen, Carlsbad, CA) containing 0.5\% D-mannose (Sigma, St. Louis, MO).

Construction of bacterial mutants. Mutations in virulence genes eae, escN, and $\mathrm{fliC}$ in strain EDL933 were induced using the $\lambda$ Red recombinase mutagenesis system and were reported previously $(13,48)$. The escN mutant was complemented with plasmid pEscN (J. L. Puente, Department of Immunobiology, University of Arizona, Tucson). The EHEC 86-24 (O157:H7) fliC mutant was constructed as described previously. The chromosom- al $\mathrm{fiC}$ gene in EHEC 86-24 was replaced with a kanamycin antibiotic resistance gene amplified from pKD4 by using forward primer G72 (AATATAGGATAACGAATCATGGCACAAGTCA TTAATACCAACTGTAGGCTGGAGCTGCTTCG) and reverse primer G73 (TTAATCAGGTTACAACGATTAACCCTGCAGC AGAGACAGAACCATATGAATATCCTCCTTA). The amplified gene segment was electroporated into bacterial cells carrying the $\lambda$ Red recombinase plasmid (pKD46). Mutants were grown on selective media, and the $f l i C$ mutation was verified via PCR utilizing primers G94 (TCCCAGCGATGAAATACTTGC) and G95 (GAGTTATCGGCATGATTATCC).

Adherence assays. Packaged baby spinach and lettuce leaves were purchased from a local store and rinsed with sterile phosphate-buffered saline (PBS, pH 7.4). No bacteria were recovered from these commercial leaves as determined by plating the rinsate onto bacterial agar plates. To infect the leaves, we employed three procedures. Leaves of approximately the same size were placed intact in petri dishes, leaves were cut into 1-cm-diameter sections and placed in 24-well plates containing $1 \mathrm{ml}$ of DMEM or filtersterilized tap water, or leaves were placed in a humid chamber improvised in a petri dish and bacteria (in $10 \mu \mathrm{l}$ ) was spotted onto them. Approximately $10^{7}$ bacteria grown overnight in LB broth were added to each sample and adherence assays were carried out between 0 to $24 \mathrm{~h}$ of infection at $4,25,37$, or $42^{\circ} \mathrm{C}$. After the desired incubation period, the leaves were washed three times with PBS with shaking, placed in 50-ml conical tubes containing glass beads in $1 \mathrm{ml}$ of sterile PBS, and ground for $1 \mathrm{~min}$ to recover bacteria for counting. Adhering bacteria were quantitated by plating 10-fold serial dilutions onto MacConkey-sorbitol agar for determination of EHEC CFU. No differences in the results were found between the three methods of infection: intact leaf in petri dishes, 1-cm leaf section in 24-well plates, or spot infection in humid chamber. Every experimental condition was tested in triplicate and repeated three times on different days. The quantitative results are the means of these three experiments. Standard deviations are represented by error bars.

Scanning electron microscopy. Leaves infected with the different $E$. coli strains were examined by scanning electron microscopy (SEM) as previously described (16). The samples were fixed with $2 \%$ formalin in PBS, postfixed with $1 \%$ osmium tetroxide, dehydrated in sequential ethanol concentrations, dried to the critical point, and coated with a mixture of gold and palladium. The specimens were examined in a high-resolution Hitachi S-4500 scanning electron microscope.

Immunofluorescence. Rabbit polyclonal antibodies raised against EHEC $\mathrm{H} 7$ flagella were available from previous studies, and their specificity has been previously described (16). For immunofluorescence, leaves fixed with $1 \%$ formalin were incubated for $1 \mathrm{~h}$ with primary rabbit anti-H7 antibodies followed by $1 \mathrm{~h}$ of incubation with secondary anti-rabbit immunoglobulin G Alexaconjugated antibodies (Molecular Probes, Eugene, OR). The specimens were mounted in glycerol-PBS and visualized under UV light and phase contrast using a Zeiss microscope.

Statistical analysis. Data corresponding to adherence assays were compared using an analysis of variance and the Tukey test from SPSS (Chicago, IL). The significance level was 5\% in all tests.

\section{RESULTS}

Spinach and lettuce colonization. To investigate how EHEC adheres to and colonizes baby spinach and lettuce leaves, we employed several experimental approaches. Initial 


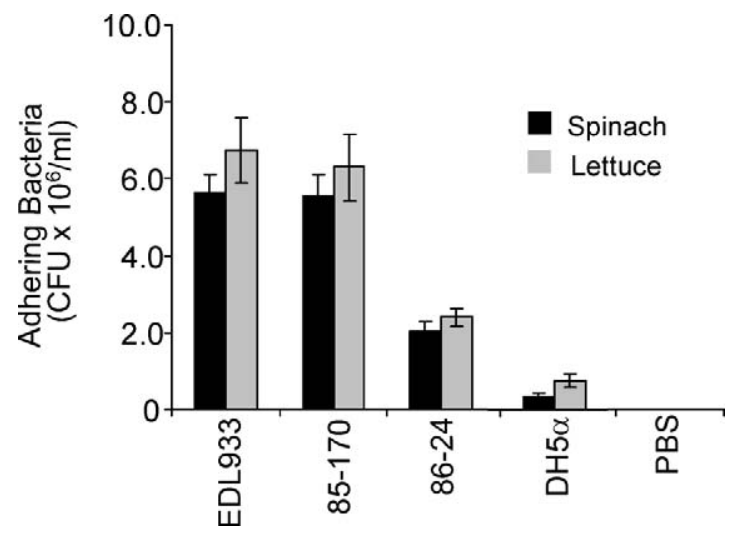

FIGURE 1. Colonization of spinach and lettuce by EHEC strains. Infection of packaged baby spinach and lettuce leaves was performed with the indicated strains for $9 \mathrm{~h}$ at $26^{\circ} \mathrm{C}$. Leaves incubated with E. coli DH5 $\alpha$ or PBS were used as negative controls. Experiments were repeated at least three times in triplicate on different days. The results (expressed as $C F U$ ) are the means of three experiments, and standard deviations (error bars) represent the mean of the three experiments performed.

experiments included adherence and kinetics assays that were performed with three different prototypic EHEC O157: H7 strains (EDL933, 85-170, and 86-24). Strain 85-170 lacks the Shiga toxin genes and thus was used to study the role of this toxin in colonization as compared with the Shigatoxigenic strains EDL933 and 86-64. The Shiga toxin favors bacterial adherence; therefore, we wanted to know whether the toxin was required for efficient leaf colonization (38). EHEC strains EDL933 and 85-170 adhered in similar numbers to spinach and lettuce leaves, whereas adherence of strain 86-24 occurred to a lesser extent. Nonvirulent laboratory strain $E$. coli $\mathrm{K}-12 \mathrm{DH} 5 \alpha$ colonization of spinach and lettuce was negligible (Fig. 1). These data collectively indicate that leaf colonization is independent of the adhesive capacity of the Shiga toxin previously described and is likely a common property of this $E$. coli pathogroup and that EHEC possesses specific plant colonization factors that are not present in nonpathogenic E. coli strains.

Colonization experiments with EDL933 were performed at $4,26,37$, and $42^{\circ} \mathrm{C}$ for $24 \mathrm{~h}$ to determine the temperature at which EHEC was most efficient at coloniz- ing spinach and lettuce leaves. No significant colonization was found at $4^{\circ} \mathrm{C}$ because of the inability of the bacteria to replicate at this temperature (data not shown). This finding suggests that refrigeration of produce should be an efficient method for preventing bacterial growth, at least during the first $24 \mathrm{~h}$ of storage. Incubation between 26 and $42^{\circ} \mathrm{C}$ was suitable for bacterial growth and produce colonization. EDL933 colonization of the spinach and lettuce was significant during the 24-h incubation time (Fig. 2). In general, higher bacterial counts were obtained from lettuce than from spinach leaves. The adherence profiles obtained between 26 and $42^{\circ} \mathrm{C}$ showed a significant increase (three- to fourfold) in bacterial counts between 6 and $9 \mathrm{~h}$ of incubation. Beyond this point, the bacteria continued to adhere in a time-dependent fashion.

Most EHEC virulence factors are more efficiently produced when the bacteria are grown in vitro in DMEM (12, $22,29)$. To investigate whether bacterial growth in this medium was a requirement for efficient leaf colonization, we compared bacterial counts from spinach and lettuce leaves in DMEM versus those in filter-sterilized tap water. The bacteria were able to colonize these leafy greens in medium, although as expected higher bacterial counts were obtained when the experiments were performed with DMEM than when they were performed with tap water (Fig. 3). These findings indicated that the bacteria would be able to replicate and survive on the leaves in the presence of municipal water. No difference was found when the bacterial inoculum was obtained from LB broth or DMEM (data not shown).

Ultrastructural analysis of the interaction of EHEC with spinach leaves. Through high-resolution SEM analysis of infected leaves, we captured EDL933 bacteria adhering randomly over the adaxial and abaxial surfaces of spinach leaves, including the areas of the stomal guard cell, whereas nonpathogenic $E$. coli K-12 DH5 $\alpha$ adhered only in small numbers to these surfaces (Fig. 4). The images of EHEC and E. coli K-12 on infected leaves in Figure 4A and $4 \mathrm{~B}$, respectively, show closed stomata. Stomal closure is a natural response by the leaf to the presence of bacterial antigens such as flagella and lipopolysaccharide (30).EHEC had long flagellalike structures protruding from the bacterial surface (Fig. 4). The electron micrographs suggest that
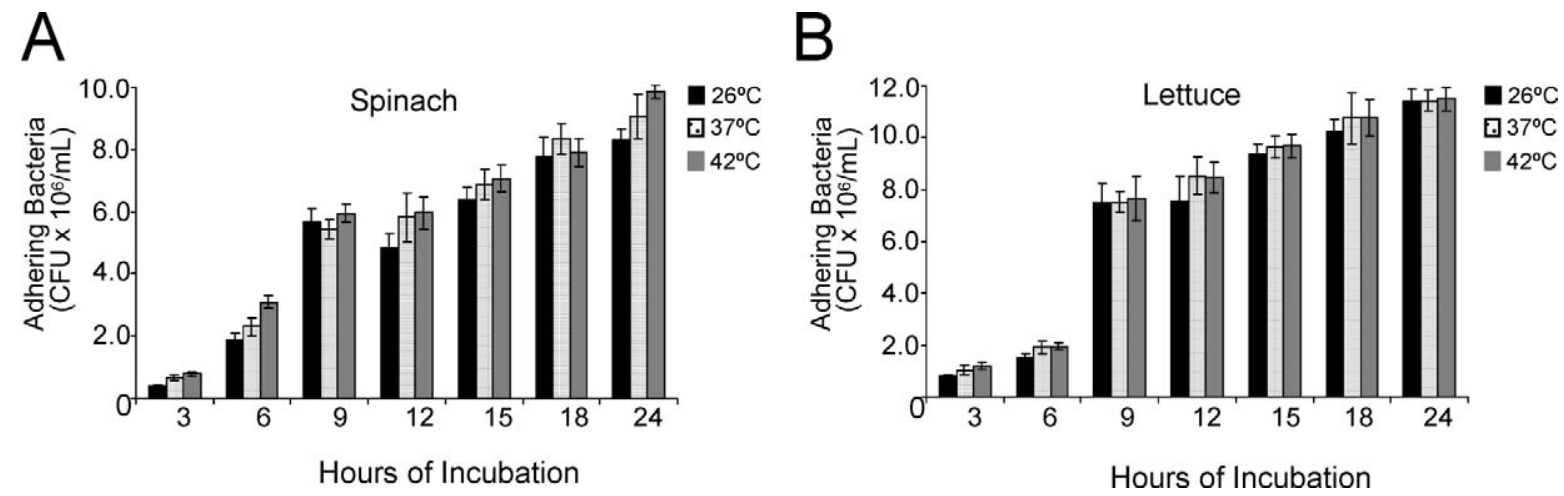

FIGURE 2. Kinetics and effect of temperature on colonization of spinach and lettuce by EHEC. Leaves of baby spinach (A) or lettuce (B) were infected between $O$ and 24 h at 26, 37, or $42^{\circ} \mathrm{C}$. The results (expressed as $C F U$ ) are the means of three experiments, and standard deviations (error bars) represent the mean of the three experiments performed. 
B

A
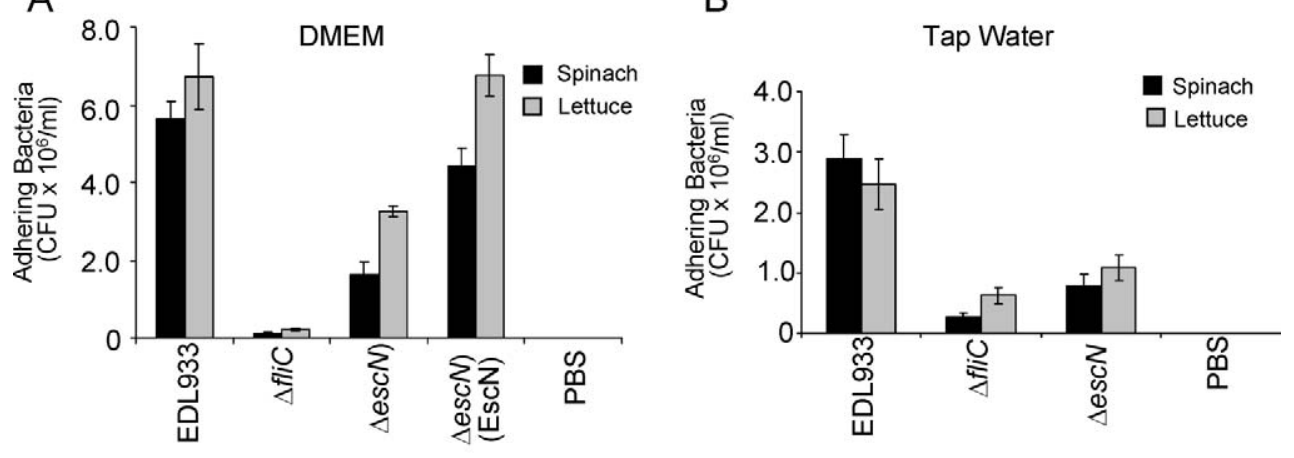

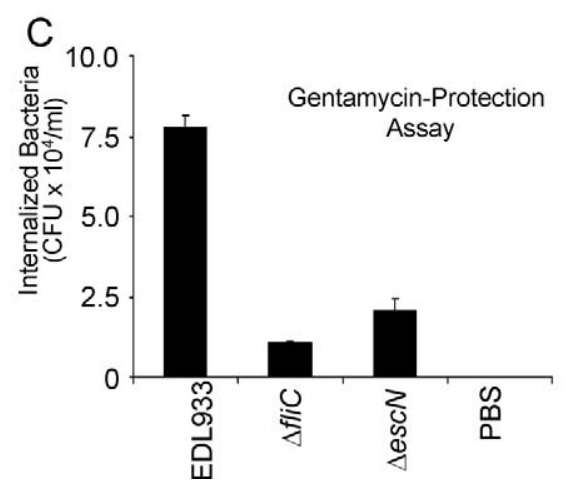

FIGURE 3. Comparative analysis of the adherence of EHEC EDL933 and isogenic mutants to spinach and lettuce leaves. Bacterial strains were incubated with spinach and lettuce leaves at $26^{\circ} \mathrm{C}$ for $9 \mathrm{~h}$ in DMEM (A) or filter-sterilized tap water (B). After washings, adherent bacteria were quantitated by plating of serial dilutions. (C) Invasion (gentamicin protection) assay for bacteria recovered after treatment of infected leaves with gentamicin for $2 \mathrm{~h}$ to kill extracellular bacteria. Experiments were repeated at least three times in triplicate on different days. The $\triangle \mathrm{fliC}$ and $\triangle \mathrm{escN}$ mutants were significantly reduced in their ability to adhere and invade spinach leaves $(\mathrm{P}<0.0001)$. The results (expressed as CFU) are the means of three experiments, and standard deviations (error bars) represent the mean of the three experiments performed.

these structures act as physical bridges between adhering bacteria and also appeared to mediate direct binding of the bacteria to the leaf surface. Confirmation of the identity of these structures as flagella came from immunofluorescence studies employing specific anti-H7 antibodies, which detected the filaments in a distinct fluorescence profile typical of flagellar structures (Fig. 4) (16). The surface of the adhering bacteria appeared covered by a fuzzy or fibrillar coating of as yet unknown nature.

Role of T3SS and flagella in spinach and lettuce colonization. To identify surface factors of EHEC mediating tropism for leafy greens, isogenic strains carrying mutations in the adhesin intimin (eae), flagella major subunit ( $f i C)$, and T3SS-associated ATPase (escN) genes were comparatively tested for leaf adherence in quantitative experiments. Intimin is the most important adhesin of EHEC, as demonstrated by human and animal epithelial cell colonization (11). In addition to their role in motility, flagella in general mediate other functions associated with pathogenicity such as adherence and invasion of epithelial cells (16), biofilm formation on abiotic surfaces (10), binding to host proteins (13), and activation of proinflammatory molecules through recognition of Toll-like receptor 5 (17). Some authors consider the T3SS an adhesin because it mediates attachment of the bacteria to host cells (33). Shaw et al. (39) described the requirement of the EspA fiber associated with the T3SS in the attachment of EHEC strains to E. vesicaria leaves, although this process was in- dependent of the protein translocation function of the T3SS. We used the EDL933 escN mutant, a strain that does not secrete effector molecules because of a mutation in the ATPase required for translocation of protein across the secreton filament (18).

Except for the intimin $\Delta e a e$ mutant, which had adherence similar to that of the parental strain (data not shown),

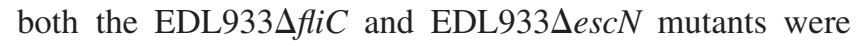
significantly hampered in their adherence to spinach and lettuce $(P<0.0001)$ (Fig. 3). A different $f i C$ mutant generated in EHEC 86-24 produces results similar to those for the EDL933 $A$ fliC mutant (data not shown). The adherence phenotype was recovered in the escN mutant after introduction of plasmid $\mathrm{pEscN}$, confirming the requirement of the T3SS in this event.

As we and others have reported $(26,27,49)$, EHEC is capable of invading cultured human epithelial cells. We hypothesized that EHEC interacting with salad leaves can penetrate the leaf surface through natural openings or wounds and become established internally, thus protected from natural or industrial foes. To test this hypothesis, we performed a gentamicin-protection assay to determine the ability of these bacteria to penetrate or invade plant cells. Infected leaves were incubated with gentamicin for $2 \mathrm{~h}$ and then homogenized, and serial dilutions were plated on MacConkey-sorbitol agar. The EHEC was capable of invading the leaf surface or penetrating through surface 

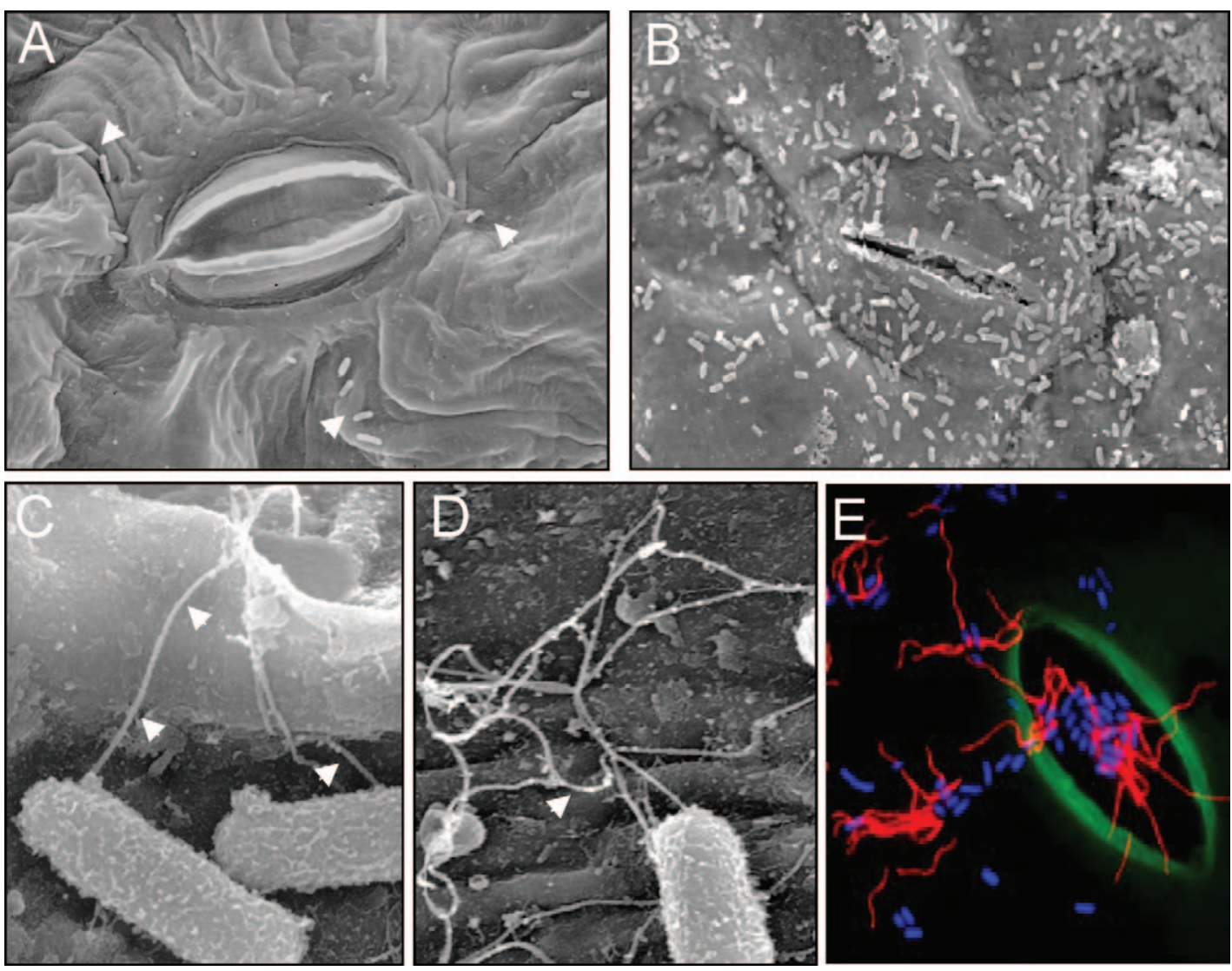

FIGURE 4. Scanning electron microscopic analysis of spinach colonized by EHEC EDL933. (A) E. coli DH5 $\alpha$, few cells (arrows) adhere to the baby spinach surface; (B through E) EHEC EDL933 cells adhere throughout the leaf surface. (C and D) High magnification electron micrographs of leaves infected with EDL933 show flagellated (arrows) bacteria; note also the presence of a fuzzy coat around the bacterial surface. (E) Immunofluorescence microscopic examination using anti-H7 antibody confirming the presence of flagella (red) on bacteria (blue) adhering to the leaf surface. Note the presence of bacteria associated with stomal guard cells (green).

wounds, allowing the bacteria to withstand bactericidal treatments (e.g., gentamicin) (Fig. 3). We also found that the flagella and T3SS mutants were significantly affected in their ability to invade spinach leaves $(P<0.0001)$ (Fig. 3C). As expected, the bacterial counts obtained with this assay were much lower than those obtained in the adherence assays performed in the absence of gentamicin, suggesting that most of the bacteria associated with the leaf are localized to the outer surfaces.

\section{DISCUSSION}

Many outbreaks of bloody diarrhea caused by EHEC infection have been associated with consumption of contaminated beef, unpasteurized milk and fruit juices, and tainted leafy greens. Recent foodborne illness episodes linked to EHEC-infected spinach and lettuce (1) suggest that there is a clear relationship between the natural bovine host, wild animals, produce, and the incidental human host. This relationship is determined by specific intrinsic factors of the bacteria, and their animal and plant hosts. This study was initiated to provide answers to important questions about the epidemiology, molecular ecology, and interaction of EHEC with spinach leaves and other leafy greens. We provide compelling experimental evidence that clearly suggests that EHEC O157:H7 colonizes the leaf outer surfaces and is able to gain access into crevices and surface wounds of leafy greens (e.g., spinach and lettuce), where it is protected from natural environmental foes and decontamination interventions in the industrial setting. The outcome of the interaction between EHEC and spinach is the survival of the bacteria and a route for transmission to and infection of humans.

Plants have developed a highly effective defense system against potential attack by bacterial pathogens. This primary immune response is referred to as PAMP (pathogen-associated molecular pattern)-triggered immunity and has evolved to recognize common features of both human and plant pathogenic bacteria (42). However, EHEC has adapted to successfully deal with the innate immunity mechanisms of plants. How this adaptation works remains an interesting subject of investigation. Melloto et al. (30) discovered that stomata in the Arabidopsis leaf epidermis function as innate immunity gates that actively prevent bacteria from entering the plant leaf. However, the authors also found that Pseudomonas syringae was capable of subverting this host defense but the human pathogen EHEC O157: H7 was not. The epidemiological data available and our data reported here argue in favor of a model in which the pathogen survives in the environment protected in the plant phyllosphere.

For many animal and plant pathogenic bacteria, the possession of a T3SS is a biological marker of their ability to inflict damage to host cells by introducing effector mol- 
ecules that hijack cytoskeleton components for their own benefit and as a mechanism for host tissue colonization (42). Many functions associated with pathogenicity are attributed to T3SS effectors, including modulation of the immune response, cytoskeleton manipulation, opening of tight junctions, penetration of host cells and tissues, cytotoxicity, and apoptosis. P. syringae uses its hrp-encoded T3SS and many effectors, including a variety of phytotoxins, to colonize and cause disease in plants $(3,6,42)$. In the present study, several lines of evidence obtained via different experimental approaches support the hypothesis of the participation of EHEC T3SS and flagella in colonization of baby spinach and lettuce leaves. We found that leaf adherence and colonization by EHEC O157:H7 is time and temperature dependent. Our observation that attachment to these leaves by the flagella and $e s c N$ isogenic mutants, which are unable to swim or translocate T3SS effector molecules, respectively, was significantly decreased is a strong indication of a flagella- and T3SS-mediated adherence mechanism. Although intimin is perhaps the most important adhesin of EHEC, it did not seem to be required for leaf colonization. High-resolution SEM and immunofluorescence microscopy with anti-H7 antibody revealed that the bacteria produce flagella structures while associated with the leaf surface. Our laboratory has published that the flagella of enteropathogenic E. coli mediate adherence of the bacteria to cultured human epithelial cells (16) and that the flagella of Stenotrophomonas maltophilia play an important role in biofilm formation on biotic and abiotic surfaces (10). Based on our past experience and the present data on EHEC flagella, we speculate that flagella play a role similar to that of adhesive structures for EHEC interacting with the surfaces of leafy greens.

The nonvirulent $E$. coli $\mathrm{K}-12$ strain $\mathrm{DH} 5 \alpha$ did not adhere to leafy greens, which strongly suggests that EHEC has multiple surface factors that specifically recognize plant cell receptors. The specific factors are unknown, but our data suggest that flagella and the T3SS are some of them. Generally, bacterial adherence to host tissues is a complex process that in many cases involves the participation of several distinct fimbrial and nonfimbrial adhesins, all of which may act at the same time or at different stages during infection with subsequent successful colonization of the host (34). Thus, we cannot rule out that other unknown factors of EHEC are important for colonization of leafy greens in natural environments. The deficient colonization of the spinach leaf apical surface by flagella and T3SS EHEC mutants provided an immediate conceptual framework to explain the molecular mechanisms of plant infection by a human pathogen. In parallel studies, we have observed that enteropathogenic E. coli, a diarrheal pathogen of young children in developing countries, also uses flagella and the T3SS to colonize leafy greens (unpublished data). Thus, it is tempting to speculate that other diarrheal bacterial pathogens that possess a T3SS and flagella such as Salmonella and enteropathogenic E. coli or flagellated enterotoxigenic $E$. coli might use a similar strategy to ensure survival in the environment and subsequent transmission into the human host, particularly in geographic regions lacking sani- tation and where agricultural fields are irrigated with sewage water. If supported, this hypothesis may help explain in part the endemicity of diarrheal diseases in certain areas of the developing world.

The elucidation of the detailed mechanisms of colonization of green produce will be important for developing strategies to prevent human EHEC infection. In this context, the novel plant-EHEC relationship should be considered an important target that deserves investigation to further our understanding of EHEC pathogenesis and ecology. Our research has shown that EHEC, a human pathogen that uses flagella and the T3SS to colonize the intestinal environment, also can employ these mechanisms to survive in the environment, making leafy greens a unique vehicle in the human disease process.

\section{ACKNOWLEDGMENTS}

We thank Dr. Michael Osterholm and Julie Ostrowsky for encouraging support and Dr. Jose L. Puente for donation of plasmid $\mathrm{pEscN}$. This work was supported by a generous grant from Fresh Express Produce.

\section{REFERENCES}

1. Armstrong, G. L., J. Hollingsworth, and J. G. Morris, Jr. 1996. Emerging foodborne pathogens: Escherichia coli O157:H7 as a model of entry of a new pathogen into the food supply of the developed world. Epidemiol. Rev. 18:29-51.

2. Ashkenazi, S., L. May, M. LaRocco, E. L. Lopez, and T. G. Cleary. 1991. The effect of postnatal age on the adherence of enterohemorrhagic Escherichia coli to rabbit intestinal cells. Pediatr. Res. 29:14-19.

3. Bender, C. L., F. Alarcon-Chaidez, and D. C. Gross. 1999. Pseudomonas syringae phytotoxins: mode of action, regulation, and biosynthesis by peptide and polyketide synthetases. Microbiol. Mol. Biol. Rev. 63:266-292.

4. Berger, C. N., R. K. Shaw, D. J. Brown, H. Mather, S. Clare, G. Dougan, M. J. Pallen, and G. Frankel. 2009. Interaction of Salmonella enterica with basil and other salad leaves. ISME J. 3:261-265.

5. Brunder, W., A. S. Khan, J. Hacker, and H. Karch. 2001. Novel type of fimbriae encoded by the large plasmid of sorbitol-fermenting enterohemorrhagic Escherichia coli $\mathrm{O} 157: \mathrm{H}(-)$. Infect. Immun. 69: 4447-4457.

6. Buttner, D., and U. Bonas. 2002. Getting across-bacterial type III effector proteins on their way to the plant cell. EMBO J. 21:5313-5322.

7. Campellone, K. G., and J. M. Leong. 2003. Tails of two Tirs: actin pedestal formation by enteropathogenic $E$. coli and enterohemorrhagic E. coli O157:H7. Curr. Opin. Microbiol. 6:82-90.

8. Caprioli, A., S. Morabito, H. Brugere, and E. Oswald. 2005. Enterohaemorrhagic Escherichia coli: emerging issues on virulence and modes of transmission. Vet. Res. 36:289-311.

9. Dean-Nystrom, E. A., B. T. Bosworth, W. C. Cray, Jr., and H. W. Moon. 1997. Pathogenicity of Escherichia coli O157:H7 in the intestines of neonatal calves. Infect. Immun. 65:1842-1848.

10. de Oliveira-Garcia, D., M. Dall'Agnol, M. Rosales, A. C. Azzuz, M. B. Martinez, and J. A. Girón. 2002. Characterization of flagella produced by clinical strains of Stenotrophomonas maltophilia. Emerg. Infect. Dis. 8:918-923.

11. Donnenberg, M. S., S. Tzipori, M. L. McKee, A. D. O’Brien, J. Alroy, and J. B. Kaper. 1993. The role of the eae gene of enterohemorrhagic Escherichia coli in intimate attachment in vitro and in a porcine model. J. Clin. Invest. 92:1418-1424.

12. Edwards, R. A., and J. L. Puente. 1998. Fimbrial expression in enteric bacteria: a critical step in intestinal pathogenesis. Trends $\mathrm{Mi}$ crobiol. 6:282-287.

13. Erdem, A. L., F. Avelino, J. Xicohtencatl-Cortes, and J. A. Girón. 2007. Host protein binding and adhesive properties of $\mathrm{H} 6$ and $\mathrm{H} 7$ flagella of attaching and effacing Escherichia coli. J. Bacteriol. 189: 7426-7435.

14. Frankel, G., O. Lider, R. Hershkoviz, A. P. Mould, S. G. Kachalsky, 
D. C. Candy, L. Cahalon, M. J. Humphries, and G. Dougan. 1996. The cell-binding domain of intimin from enteropathogenic Escherichia coli binds to $\beta_{1}$ integrins. J. Biol. Chem. 271:20359-20364.

15. Frenzen, P. D., A. Drake, and F. J. Angulo. 2005. Economic cost of illness due to Escherichia coli O157 infections in the United States. J. Food Prot. 68:2623-2630.

16. Girón, J. A., A. G. Torres, E. Freer, and J. B. Kaper. 2002. The flagella of enteropathogenic Escherichia coli mediate adherence to epithelial cells. Mol. Microbiol. 44:361-379.

17. Hayashi, F., K. D. Smith, A. Ozinsky, T. R. Hawn, E. C. Yi, D. R. Goodlett, J. K. Eng, S. Akira, D. M. Underhill, and A. Aderem. 2001. The innate immune response to bacterial flagellin is mediated by Toll-like receptor 5. Nature 410:1099-1103.

18. Jarvis, K. G., J. A. Girón, A. E. Jerse, T. K. McDaniel, M. S. Donnenberg, and J. B. Kaper. 1995. Enteropathogenic Escherichia coli contains a putative type III secretion system necessary for the export of proteins involved in attaching and effacing lesion formation. Proc. Natl. Acad. Sci. USA 92:7996-8000.

19. Jarvis, K. G., and J. B. Kaper. 1996. Secretion of extracellular proteins by enterohemorrhagic Escherichia coli via a putative type III secretion system. Infect. Immun. 64:4826-4829.

20. Kaper, J. B., J. P. Nataro, and H. L. Mobley. 2004. Pathogenic Escherichia coli. Nat. Rev. Microbiol. 2:123-140.

21. Karmali, M. A., B. T. Steele, M. Petric, and C. Lim. 1983. Sporadic cases of haemolytic-uraemic syndrome associated with faecal cytotoxin and cytotoxin-producing Escherichia coli in stools. Lancet i: 619-620.

22. Kenny, B., A. Abe, M. Stein, and B. B. Finlay. 1997. Enteropathogenic Escherichia coli protein secretion is induced in response to conditions similar to those in the gastrointestinal tract. Infect. Immun. 65:2606-2612.

23. Kenny, B., and B. B. Finlay. 1997. Intimin-dependent binding of enteropathogenic Escherichia coli to host cells triggers novel signaling events, including tyrosine phosphorylation of phospholipase C-gamma1. Infect Immun. 65:2528-2536.

24. Kim, S. H., and Y. H. Kim. 2004. Escherichia coli O157:H7 adherence to HEp-2 cells is implicated with curli expression and outer membrane integrity. J. Vet. Sci. 5:119-124.

25. Low, A. S., F. Dziva, A. G. Torres, J. L. Martinez, T. Rosser, S. Naylor, K. Spears, N. Holden, A. Mahajan, J. Findlay, J. Sales, D. G. Smith, J. C. Low, M. P. Stevens, and D. L. Gally. 2006. Cloning, expression, and characterization of fimbrial operon F9 from enterohemorrhagic Escherichia coli O157:H7. Infect. Immun. 74:2233-2244.

26. Luck, S. N., L. Badea, V. Bennett-Wood, R. Robins-Browne, and E. L. Hartland. 2006. Contribution of FliC to epithelial cell invasion by enterohemorrhagic Escherichia coli O113:H21. Infect. Immun. 74:6999-7004.

27. Luck, S. N., V. Bennett-Wood, R. Poon, R. M. Robins-Browne, and E. L. Hartland. 2005. Invasion of epithelial cells by locus of enterocyte effacement-negative enterohemorrhagic Escherichia coli. Infect. Immun. 73:3063-3071.

28. McKee, M. L., A. R. Melton-Celsa, R. A. Moxley, D. H. Francis, and A. D. O'Brien. 1995. Enterohemorrhagic Escherichia coli O157: $\mathrm{H} 7$ requires intimin to colonize the gnotobiotic pig intestine and to adhere to HEp-2 cells. Infect. Immun. 63:3739-3744.

29. Mellies, J. L., A. M. Barron, and A. M. Carmona. 2007. Enteropathogenic and enterohemorrhagic Escherichia coli virulence gene regulation. Infect. Immun. 75:4199-4210.

30. Melotto, M., W. Underwood, J. Koczan, K. Nomura, and S. Y. He. 2006. Plant stomata function in innate immunity against bacterial invasion. Cell 126:969-980.

31. Naylor, S. W., J. C. Low, T. E. Besser, A. Mahajan, G. J. Gunn, M. C. Pearce, I. J. McKendrick, D. G. Smith, and D. L. Gally. 2003. Lymphoid follicle-dense mucosa at the terminal rectum is the principal site of colonization of enterohemorrhagic Escherichia coli O157:H7 in the bovine host. Infect. Immun. 71:1505-1512.

32. Nicholls, L., T. H. Grant, and R. M. Robins-Browne. 2000. Identification of a novel genetic locus that is required for in vitro adhesion of a clinical isolate of enterohaemorrhagic Escherichia coli to epithelial cells. Mol. Microbiol. 35:275-288.

33. Nougayrede, J. P., P. J. Fernandes, and M. S. Donnenberg. 2003. Adhesion of enteropathogenic Escherichia coli to host cells. Cell Microbiol. 5:359-372.

34. Ofek, I., D. L. Hasty, and R. J. Doyle. 2003. Adhesins as bacterial cell surface structures: general concepts of structures, biogenesis, and regulation, p. 63-96. In Bacterial adhesion to animal cells and tissues. ASM Press, Washington, DC.

35. Paton, J. C., and A. W. Paton. 1998. Pathogenesis and diagnosis of Shiga toxin-producing Escherichia coli infections. Clin. Microbiol. Rev. 11:450-479.

36. Rendon, M. A., Z. Saldaña, A. L. Erdem, V. Monteiro-Neto, A. Vazquez, J. B. Kaper, J. L. Puente, and J. A. Girón. 2007. Commensal and pathogenic Escherichia coli use a common pilus adherence factor for epithelial cell colonization. Proc. Natl. Acad. Sci. USA 104: 10637-10642.

37. Riley, L. W., R. S. Remis, S. D. Helgerson, H. B. McGee, J. G. Wells, B. R. Davis, R. J. Hebert, E. S. Olcott, L. M. Johnson, N. T. Hargrett, P. A. Blake, and M. L. Cohen. 1983. Hemorrhagic colitis associated with a rare Escherichia coli serotype. N. Engl. J. Med. 308:681-685.

38. Robinson, C. M., J. F. Sinclair, M. J. Smith, and A. D. O'Brien. 2006. Shiga toxin of enterohemorrhagic Escherichia coli type O157: H7 promotes intestinal colonization. Proc. Natl. Acad. Sci. USA 103: 9667-9672.

39. Shaw, R. K., C. N. Berger, B. Feys, S. Knutton, M. J. Pallen, and G. Frankel. 2008. Enterohemorrhagic Escherichia coli exploits EspA filaments for attachment to salad leaves. Appl. Environ. Microbiol. 74:2908-2914.

40. Solomon, E. B., S. Yaron, and K. R. Matthews. 2002. Transmission of Escherichia coli O157:H7 from contaminated manure and irrigation water to lettuce plant tissue and its subsequent internalization. Appl. Environ. Microbiol. 68:397-400.

41. Srimanote, P., A. W. Paton, and J. C. Paton. 2002. Characterization of a novel type IV pilus locus encoded on the large plasmid of locus of enterocyte effacement-negative Shiga-toxigenic Escherichia coli strains that are virulent for humans. Infect. Immun. 70:3094-3100.

42. Staskawicz, B. J., M. B. Mudgett, J. L. Dangl, and J. E. Galan. 2001. Common and contrasting themes of plant and animal diseases. Science 292:2285-2289.

43. Stavric, S., B. Buchanan, and T. M. Gleeson. 1993. Intestinal colonization of young chicks with Escherichia coli O157:H7 and other verotoxin-producing serotypes. J. Appl. Bacteriol. 74:557-563.

44. Tarr, P. I., S. S. Bilge, J. C. Vary, Jr., S. Jelacic, R. L. Habeeb, T. R. Ward, M. R. Baylor, and T. E. Besser. 2000. Iha: a novel Escherichia coli $\mathrm{O} 157: \mathrm{H7}$ adherence-conferring molecule encoded on a recently acquired chromosomal island of conserved structure. Infect. Immun. 68:1400-1407.

45. Tarr, P. I., M. A. Neill, C. R. Clausen, J. W. Newland, R. J. Neill, and S. L. Moseley. 1989. Genotypic variation in pathogenic Escherichia coli $\mathrm{O} 157$ :H7 isolated from patients in Washington, 19841987. J. Infect. Dis. 159:344-347.

46. Torres, A. G., J. A. Girón, N. T. Perna, V. Burland, F. R. Blattner, F. Avelino-Flores, and J. B. Kaper. 2002. Identification and characterization of $\operatorname{lp} f A B C C^{\prime} D E$, a fimbrial operon of enterohemorrhagic Escherichia coli O157:H7. Infect. Immun. 70:5416-5427.

47. Tzipori, S., H. Karch, K. I. Wachsmuth, R. M. Robins-Browne, A. D. O'Brien, H. Lior, M. L. Cohen, J. Smithers, and M. M. Levine. 1987. Role of a 60-megadalton plasmid and Shiga-like toxins in the pathogenesis of infection caused by enterohemorrhagic Escherichia coli $\mathrm{O} 157: \mathrm{H} 7$ in gnotobiotic piglets. Infect. Immun. 55:3117-3125.

48. Xicohtencatl-Cortes, J., V. Monteiro-Neto, M. A. Ledesma, D. M. Jordan, O. Francetic, J. B. Kaper, J. L. Puente, and J. A. Girón. 2007. Intestinal adherence associated with type IV pili of enterohemorrhagic Escherichia coli O157:H7. J. Clin. Invest. 117:3519-3529.

49. Xicohtencatl-Cortes, J., V. Monteiro-Neto, Z. Saldaña, M. A. Ledesma, J. L. Puente, and J. A. Girón. 2009. The type 4 pili of enterohemorrhagic Escherichia coli O157:H7 are multipurpose structures with pathogenic attributes. J. Bacteriol. 191:411-421. 